\title{
Physicochemical surface properties of bacterial cellulose/polymethacrylate nanocomposites: an approach by inverse gas chromatography
}

\author{
Marisa Faria $^{\mathrm{a}}$, Carla Vilela ${ }^{\mathrm{b}, * *}$, Armando J.D. Silvestre ${ }^{\mathrm{b}}$, Bhanumathyamma Deepa ${ }^{\mathrm{c}, \mathrm{d}}$, \\ Matic Resnik ${ }^{\mathrm{e}}$, Carmen S.R. Freire ${ }^{\mathrm{b}}$, Nereida Cordeiro ${ }^{\mathrm{a}, \mathrm{f}, *}$ \\ ${ }^{a}$ LB3, Faculty of Exact Science and Engineering, University of Madeira, 9000-390 Funchal, Portugal \\ ${ }^{\mathrm{b}}$ CICECO - Aveiro Institute of Materials, Department of Chemistry, Campus de Santiago, University of Aveiro, 3810-193, Aveiro, Portugal \\ ${ }^{\mathrm{c}}$ Department of Chemistry, C.M.S. College, Kottayam, 686001, Kerala, India \\ ${ }^{\mathrm{d}}$ Department of Chemistry, Bishop Moore College, Mavelikara 690101, Kerala, India \\ ${ }^{\mathrm{e}}$ Jožef Stefan Institute, IJS, Department of Surface Engineering and Optoelectronics, Ljubljana, Slovenia \\ ${ }^{\mathrm{f}}$ CIIMAR - Interdisciplinary Centre of Marine and Environmental Research, University of Porto, 4450-208, Porto, Portugal
}

\section{A R T I C L E I N F O}

\section{Keywords:}

Bacterial cellulose

Nanocomposites

Poly(glycidyl methacrylate)

Poly(poly(ethylene glycol) methacrylate)

Surface properties

Inverse gas chromatography

\begin{abstract}
A B S T R A C T
Nanocomposites of poly(glycidyl methacrylate) and bacterial cellulose (BC), or poly(poly(ethylene glycol) methacrylate) and BC were produced via the in-situ polymerization of methacrylic monomers, inside the BC 3D network. The nanocomposites surface properties were evaluated by inverse gas chromatography (IGC). The dispersive component of surface energy $\left(\gamma_{s}^{d}\right)$ varied between $35.64-83.05 \mathrm{~mJ} \mathrm{~m}^{-2}$ at $25^{\circ} \mathrm{C}$. The surface of the different nanocomposites has a predominant basic character $\left(K_{\mathrm{b}} / K_{\mathrm{a}}=4.20-4.31\right)$. Higher specific interactions with polar probes were found for the nanocomposite bearing pendant epoxide groups, that apart from the low surface area $\left(S_{B E T}=0.83 \mathrm{~m}^{2} \mathrm{~g}^{-1}\right)$ and monolayer capacity $\left(n_{m}=2.18 \mu \mathrm{mol} \mathrm{g}^{-1}\right)$, exhibits a high value of $\gamma_{s}^{d}$ $\left(88.19 \mathrm{~mJ} \mathrm{~m}^{-2}\right.$ at $\left.20^{\circ} \mathrm{C}\right)$. These results confirm the potential of IGC to differentiate between nanocomposites with different surface functional groups and to predict their potential interactions with living tissues, body fluids and other materials.
\end{abstract}

\section{Introduction}

The design of functional, nanostructured and high-performance composite materials based on bacterial cellulose (BC), i.e. an extracellular form of nanocellulose produced by non-pathogenic bacteria that presents remarkable properties, is of utmost importance for myriad applications particularly in the biomedical and pharmaceutical fields (Silvestre, Freire, \& Neto, 2014; Ullah, Santos et al., 2016; Ullah, Wahid et al., 2016). One of the methodologies that is gaining a lot of attention to prepare BC-based nanocomposites, due to its simplicity, is the socalled in-situ polymerization of functional monomers within the BC porous network that originates materials with interesting properties for application as, for instance, stimuli-responsive nanocomposites for drug delivery (Saïdi, Vilela, Oliveira, Silvestre, \& Freire, 2017), antimicrobial hydrogels (Figueiredo et al., 2015) and ion exchange membranes for fuel cells (Gadim et al., 2014). This approach has been used in particular with acrylic or methacrylic monomers (Amin, Ahmad, Halib, \& Ahmad, 2012; Buyanov, Gofman, Revel'skaya, Khripunov, \&
Tkachenko, 2010; Figueiredo et al., 2013, 2015; Hobzova, DuskovaSmrckova, Michalek, Karpushkin, \& Gatenholm, 2012; Saïdi et al., 2017; Vilela, Gadim, Silvestre, Freire, \& Figueiredo, 2016, 2017), but also with other monomer types (Mashkour, Rahimnejad, \& Mashkour, 2016; Gadim et al., 2014). The incorporation of these polymers within the $\mathrm{BC}$ porous structure generates nanostructured materials with different mechanical, thermal, viscoelastic, optical and surface properties. The latter properties are particularly relevant in the context of composite materials whose surface will interact with, for example, living tissues, body fluids or water contaminants, where adsorption and/or adhesion processes dictate their suitability for specific applications (Mohammadi-Jam \& Waters, 2014).

Inverse gas chromatography (IGC) is one of the most used techniques to examine the physicochemical surface properties of non-volatile solid materials in the form of films, fibres and powders with both amorphous and crystalline nature, and different morphologies (Lapčík et al., 2016; Mohammadi-Jam \& Waters, 2014). The simultaneous measurement of physical and chemical properties by IGC allows to

\footnotetext{
* Corresponding author at: LB3, Faculty of Exact Science and Engineering, University of Madeira, 9000-390 Funchal, Portugal.

*** Corresponding author.

E-mail addresses: cvilela@ua.pt (C. Vilela), ncordeiro@staff.uma.pt (N. Cordeiro).
} 
Table 1

Composition in weight fraction of the prepared nanocomposites in the dry state.

\begin{tabular}{|c|c|c|c|c|c|}
\hline \multirow[t]{2}{*}{ Nanocomposites } & \multicolumn{2}{|c|}{ Nominal composition } & \multicolumn{3}{|c|}{ Measured composition } \\
\hline & $w_{\text {monomer }} / w_{\mathrm{BC}}$ & $w_{\mathrm{MBA}} / w_{\text {monomer }}$ & $w_{\text {polymer }} / w_{\mathrm{BC}}$ & $w_{\mathrm{BC}} / w_{\text {Total }}$ & $w_{\text {polymer }} / w_{\text {Total }}$ \\
\hline PGMA/BC & 2.0 & 0.0 & 1.56 & 0.39 & 0.61 \\
\hline PGMA-MBA/BC & 2.0 & 0.2 & 2.03 & 0.33 & 0.67 \\
\hline PPEGMA/BC & 20.0 & 0.0 & 6.69 & 0.13 & 0.87 \\
\hline
\end{tabular}

envisage the surface behaviour of a given sample in contact with other materials, as well as to determine how the fabrication method can influence the surface properties (Mohammadi-Jam \& Waters, 2014). As an illustrative example, Beaumont et al. demonstrated that the drying method (freeze-drying and supercritical drying) applied to cellulose II gel (TENCEL ${ }^{\circledast}$ ) influenced the surface properties of the obtained cellulose particles, with the supercritical drying yielding aerogels of higher surface area (Beaumont et al., 2017).

The IGC tool has already made its debut in the evaluation of the surface properties of $\mathrm{BC}$, its derivatives and composite materials (Alonso, Faria, Mohammadkazemi, et al., 2018; Alonso, Faria, Ferreira, \& Cordeiro, 2018; Castro et al., 2015; Mohammadkazemi, Aguiar, \& Cordeiro, 2017). These studies enabled the assessment of the surface physicochemical changes endowed by chemical (e.g. in-situ glyoxalization of BC (Castro et al., 2015) or physical (e.g. oxidative polymerization of aniline inside the porous network and surface of BC (Alonso, Faria, Mohammadkazemi, et al., 2018; Alonso, Faria, Ferreira, et al., 2018) modification in terms of surface energy, polarity and acid-base behaviour because of the interactions with polar and non-polar probes.

In this context and following our interest on natural-based materials and the assessment of their surface properties, the purpose of the present work is to gain a thorough understanding of the surface properties of BC-based nanocomposites with different surface groups by using IGC analysis. Nanocomposite materials were prepared via the in-situ free radical polymerization of methacrylic monomers, containing either epoxide or hydroxyl pendent groups, namely poly(glycidyl methacrylate) (PGMA) or poly(poly(ethylene glycol) methacrylate) (PPEGMA), respectively, inside the $\mathrm{BC}$ porous structure, to evaluate the influence of different surface groups on specific interactions, namely surface energy, surface area, monolayer capacity and acid-base properties.

\section{Materials and methods}

\subsection{Chemicals and materials}

Bacterial cellulose (BC) was biosynthesized in the form of wet membranes using the Gluconacetobacter sacchari bacterial strain (Trovatti, Serafim, Freire, Silvestre, \& Neto, 2011). Briefly, the BC membranes were produced by growing the $G$. sacchari microorganisms in static conditions at $30^{\circ} \mathrm{C}$ during $48 \mathrm{~h}$ in HS (Hestrin-Schramm) liquid medium $\left(20 \mathrm{gL}^{-1}\right.$ glucose, $5 \mathrm{~g} \mathrm{~L}^{-1}$ peptone, $5 \mathrm{gL}^{-1}$ yeast extract, $2.7 \mathrm{~g} \mathrm{~L}^{-1} \mathrm{Na}_{2} \mathrm{HPO}_{4}$ and $1.15 \mathrm{~g} \mathrm{~L}^{-1}$ citric acid, $\mathrm{pH}$ 5). After incubation, the $\mathrm{BC}$ membranes were separated from the media, treated with $0.5 \mathrm{M}$ $\mathrm{NaOH}\left(90^{\circ} \mathrm{C}\right.$ during $\left.30 \mathrm{~min}\right)$ to eliminate the attached cells, washed with distilled water until neutral $\mathrm{pH}$, whitened with a $1 \%$ hypochlorite solution and washed with distilled water.

Poly(ethylene glycol) methacrylate (PEGMA, average $M_{n} 500$, containing $900 \mathrm{ppm}$ monomethyl ether hydroquinone as inhibitor), glycidyl methacrylate (GMA, 97\%, with $100 \mathrm{ppm}$ of monomethyl ether hydroquinone as inhibitor), $N, N$ '-methylenebisacrylamide (MBA, $\geq$ 99.5\%) and ammonium persulphate (APS) (98\%) were purchased from Sigma-Aldrich and used as received. The chemical reagents used for IGC measurements (non-polar and polar molecules, > 99\% purity, chromatography grade) were also purchased from Sigma-Aldrich. Methane (reference probe, $>99.99 \%$ ) and helium (carrier gas, $>99.99 \%$ ) were supplied by Air Liquid Company.

\subsection{Preparation of BC-based nanocomposites}

The in-situ free radical polymerization of GMA inside the BC network was adapted from the procedure described elsewhere (Figueiredo et al., 2015). First, wet BC membranes were weighed and about $60 \%$ of their water content was drained. Then, two distinct aqueous reaction mixtures were prepared: one containing GMA in a ratio of $1: 2\left(w_{\mathrm{BC}}\right)$ $w_{\mathrm{GMA}}$ ) and $0.5 \%$ APS ( $\mathrm{w} / \mathrm{w}$ relative to monomer), and another containing the same amounts of monomer and radical initiator, and $20 \%$ MBA ( $w / w$ relative to monomer). The drained membranes and reaction mixtures were both purged with $\mathrm{N}_{2}$ for $30 \mathrm{~min}$. Each reaction mixture was added to the $\mathrm{BC}$ membranes and left for $1 \mathrm{~h}$ at room temperature for complete incorporation inside the $\mathrm{BC}$ network. The polymerization reaction took place in an oil bath for $6 \mathrm{~h}$ at $60^{\circ} \mathrm{C}$. The obtained nanocomposites (Table 1) were washed with distilled water and dried at $40^{\circ} \mathrm{C}$.

The in-situ free radical polymerization of PEGMA inside the BC network was carried out according to the procedure described above but with a $\mathrm{BC}$ to monomer ratio of 1:20 ( $\left.w_{\mathrm{BC}} / w_{\mathrm{PEGMA}}\right)$ and $0.5 \%$ APS ( $\mathrm{w} / \mathrm{w}$ relative to monomer).

\subsection{Water uptake capacity}

The water uptake $(W U)$ of the nanocomposites was determined by immersing the samples $\left(1 \times 1 \mathrm{~cm}^{2}\right)$ in distilled water at room temperature with a minimum of three replicas. The weight increase was periodically measured for a period of $48 \mathrm{~h}$. For each measurement, the samples were taken out of the water, their wet surfaces immediately wiped dry with filter paper, weighed, and then re-immersed. The water uptake was calculated using the equation:

$W U(\%)=\frac{\left(W_{w}-W_{0}\right)}{w_{0}} \times 100 \%$

where, $W_{w}$ is the sample weight after immersion in water and $W_{0}$ is the initial weight of dry sample.

\subsection{X-ray diffraction}

The X-ray diffraction (XRD) measurements were carried out with a Phillips X'pert MPD diffractometer using $\mathrm{Cu} K \alpha$ radiation $(\lambda=1.541 \AA)$ with a scan rate of $0.05^{\circ} \mathrm{s}^{-1}$ (in $2 \theta$ scale). The peaks were deconvoluted using Pearson VII peak functions (Peakfit software) for crystallinity index, $I_{C}$ :

$I_{C}=1-\frac{I_{a m}}{I_{002}} \times 100 \%$

where $I_{002}$ is the maximum peak intensity at $2 \theta$ around $22^{\circ}$, representing the crystalline region of cellulose, and $I_{a m}$ is the minimum peak intensity at $2 \theta$ around $18^{\circ}$, representing the amorphous region of cellulose (Jiang \& Hsieh, 2014).

\subsection{Attenuated total reflectance - Fourier transform infrared spectroscopy}

The infrared spectra were obtained by Attenuated total reflectionFourier transform infrared spectroscopy (ATR-FTIR), using a Perkin Elmer Spectrum Two coupled with a Diamond ATR accessory 
a)<smiles>C=C(C)C(=O)OCC1CO1</smiles>

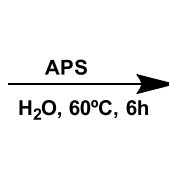<smiles>CCC(C)(C)C(C)(C)C(=O)OCC1CO1</smiles>

GMA

b)<smiles>C=C(C)C(=O)OCC1CO1</smiles><smiles>C=CC(=O)NCNC(=O)C=C</smiles>

MBA
PGMA

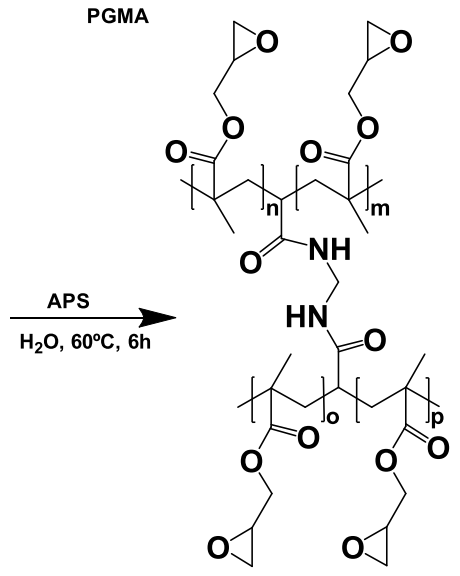

PGMA-MBA c)

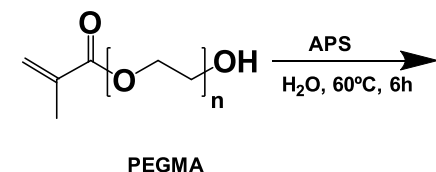

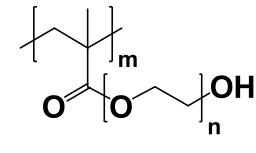

PPEGMA

Fig. 1. Radical polymerization of GMA in the (a) absence and (b) presence of cross-linker (MBA), and (c) radical polymerization of PEGMA.

(DurasamplIR II, Smiths Detection, UK). 32 scans were acquired in the range of $4000-700 \mathrm{~cm}^{-1}$, with a wavenumber resolution of $4 \mathrm{~cm}^{-1}$.

\subsection{Scanning electron microscopy and energy-dispersive X-ray spectroscopy}

Scanning electron microscopy (SEM) images of the sample surfaces were obtained in a HR-FESEM SU-70 Hitachi equipment, operating at $4.0 \mathrm{kV}$ in the field emission mode. Samples were deposited on a steel plate and coated with carbon before the analysis. The semi-quantitative elemental chemical compositions of the samples were determined by energy-dispersive X-ray spectroscopy (EDS). Semi-quantitative analyses (wt.\%) were carried out for carbon, oxygen and nitrogen, and the $\mathrm{C} / \mathrm{O}$ ratio was obtained. EDS experiments were conducted at an accelerated voltage of $5 \mathrm{kV}$ in a Hitachi SU 8090 equipment.

\subsection{Atomic force microscopy}

The morphological features of the samples were analysed through atomic force microscopy (AFM; Solver PRO, NT-MDT, Russia) in the tapping mode in air. The samples were scanned with the standard $\mathrm{Si}$ (silicon) cantilever, with a constant force of $22 \mathrm{~N} \mathrm{~m}^{-1}$, and at a resonance frequency of $325 \mathrm{kHz}$ (tip radius: $10 \mathrm{~nm}$ and tip length: $95 \mu \mathrm{m}$ ). Surface roughness $\left(R_{a}\right)$ was measured from representative images on $5 \times 5 \mu \mathrm{m}^{2}$ areas and the scan rate was set to $1.3 \mathrm{~Hz}$. Average surface roughness and standard deviation were calculated from at least 3 different measurements on different areas of the same sample.

\subsection{Inverse gas chromatography}

Inverse gas chromatography (IGC) measurements were carried out on a commercial inverse gas chromatograph (iGC, Surface Measurements Systems, London, UK) equipped with flame ionization (FID) and thermal conductivity (TCD) detectors. The iGC system is fully

automatic with SMS iGC Controller v1.8 control software. Data were analysed using iGC Standard v1.3 and Advanced Analysis Software v1.25.

The samples were packed in standard glass silanized (dimethyldichlorosilane; Repelcote BDH, UK) columns with $0.2 \mathrm{~cm}$ internal diameter and $30 \mathrm{~cm}$ in length by vertical tapping, for about $2 \mathrm{~h}$. The columns with the samples were conditioned for $8 \mathrm{~h}$. After conditioning, pulse injections were carried out with a $0.25 \mathrm{~mL}$ gas loop. Four $n$-alkanes (heptane, octane, nonane and decane) were used for measurements of the dispersive component of surface energy at 20, 25 and $30^{\circ} \mathrm{C}$. Four polar probes (tetrahydrofuran (THF), dichloromethane (DCM), acetonitrile (ACN) and ethyl acetate (ETOAc)) were used to determine the specific component of surface energy and acid-base surface characteristics $\left(K_{A}\right.$ and $\left.K_{B}\right)$ at $25^{\circ} \mathrm{C}$. The isotherm experiments were undertaken with $n$-octane, THF and DCM at $25^{\circ} \mathrm{C}$. All experiments were carried out at $0 \%$ relative humidity with a helium flow rate of $10 \mathrm{ml} \mathrm{min}^{-1}$, at least in duplicate, producing a reproducibility error of less than $4 \%$.

The theoretical analysis and calculation of the surface energy component, acid-base character and isotherm measurements is thoroughly described in the relevant literature (Alonso, Faria, Ferreira, et al., 2018; Cordeiro, Gouveia, Moraes, \& Amico, 2011; Lapčík et al., 2016; Mohammadi-Jam \& Waters, 2014).

\subsection{Multivariate statistical analysis}

Cluster analysis was performed by MINITAB 17 Statistical Software. The hierarchically agglomerative clustering was used to evaluate and achieve the similarity between IGC, AFM and EDS data through the linkage distance (Square Euclidean distance), using the Ward linkage. The dispersive component of surface free energy $\left(\gamma_{s}^{d}\right)$, adsorption potential $\left(A_{\max }\right)$ of $n$-octane, acid-base character $\left(K_{b} / K_{a}\right)$ ratio, specific component of surface free energy $\left(\Delta G_{s}^{s p}\right)$, surface area $\left(S_{B E T}\right)$, roughness $\left(R_{a}\right)$ and $C / O$ ratio were the variables introduced for the agglomerative method.

\section{Results and discussion}

In the present study, three BC-based nanocomposite materials were prepared via the in-situ free radical polymerization of a methacrylic monomer, namely GMA and PEGMA (respectively bearing an epoxide and hydroxyl pendent group), inside the BC three-dimensional network. The reaction schemes of GMA polymerization in the presence and absence of cross-linker, as well as the polymerization of PEGMA are summarized in Fig. 1. GMA was selected because it is a versatile and low-cost commercial monomer used to obtain a hydrophobic homopolymer but also sophisticated (co)polymers that can be further functionalized through nucleophilic epoxy ring opening reactions (Muzammil, Khan, \& Stuparu, 2017), which contributes to widen their range of application. On the other hand, PEGMA was chosen due to its amphiphilic nature resulting from the water-soluble side chain and the hydrophobic methacrylate group that originates (co)polymers with interesting properties (Bozkurt \& Karadedeli, 2007; Guzmán, Nava, Vazquez-Arenas, \& Cardoso, 2017). Only PGMA was synthesized in the presence or absence of cross-linker to assess the influence of using a cross-linked and non-cross-linked matrix on the surface properties of the corresponding nanocomposites.

The whitish and opaque PGMA/BC nanocomposites are composed of 61 wt.\% (PGMA/BC) and 67 wt.\% (PGMA-MBA/BC) of PGMA, while the yellowish and translucent PPEGMA/BC nanocomposite contains 87 wt.\% of PPEGMA (Table 1). The EDS data (Table 2) showed that the $C / O$ ratio increased around $36 \%$ and $34 \%$ for PGMA/BC $(C / O=4.50)$ and PGMA-MBA/BC $(C / O=4.41)$, respectively, but decreased about $12 \%$ for PPEGMA/BC $(C / O=2.90)$, when compared with the $C / O$ ratio of the native $\mathrm{BC}(C / O=3.30)$. These results bear out the incorporation of PGMA, cross-linked PGMA and PPEGMA into the BC three- 
Table 2

EDS elemental composition, water uptake capacity $(W U)$, crystallinity index $\left(I_{\mathrm{c}}\right)$ and average surface roughness $\left(R_{\mathrm{a}}\right)$ of BC, PGMA/BC, PGMA-MBA/BC and PPEGMA/BC.

\begin{tabular}{lllllll}
\hline Nanocomposites & $C$ & $O$ & $C / O$ & $W U / \%$ & $I_{c} / \%$ & $R_{a} / \mathrm{nm}$ \\
\hline BC & 75.37 & 23.05 & 3.30 & 138 & 95.0 & $37.7 \pm 1.3$ \\
PGMA/BC & 80.70 & 17.90 & 4.50 & 33 & 69.0 & $34.5 \pm 16.6$ \\
PGMA-MBA/BC & 72.37 & 16.41 & 4.41 & 31 & 56.5 & $51.4 \pm 2.1$ \\
PPEGMA/BC & 73.14 & 25.23 & 2.90 & 432 & 39.4 & $26.8 \pm 0.1$ \\
\hline
\end{tabular}

dimensional network. Furthermore, PGMA/BC and PGMA-MBA/BC are both hydrophobic nanocomposites with a low water uptake capacity of 33 and 31\%, respectively, whereas BC and PPEGMA/BC are hydrophilic with water uptake values of 138 and $432 \%$ (Table 2 ).

Regarding the crystallinity index $\left(I_{c}\right.$, Table 2$)$ of the nanocomposites, it increased with the increasing content of BC $\left(I_{\mathrm{c}}=65-79 \%\right.$ (Pecoraro, Manzani, Messaddeq, \& Ribeiro, 2008)) from $39.4 \%$ for PPEGMA/BC (13 wt. $\%$ of BC) to $56.5 \%$ for PGMA-MBA/BC (33 wt. $\%$ of $\mathrm{BC}$ ) and $69.0 \%$ for PGMA/BC (39 wt.\% of BC). This was expected given that both PGMA (cross-linked and non-cross-linked) and PPEGMA are amorphous polymers. The crystalline or amorphous nature of the materials is one of the parameters that can influence the IGC measurements and, hence, the surface properties (Gamelas, 2013; Planinšek \& Buckton, 2003).

Fig. 2 shows the ATR-FTIR spectra of pure BC, and PGMA/BC, PGMA-MBA/BC and PPEGMA/BC nanocomposites. The FTIR spectrum of $\mathrm{BC}$ displays the typical absorption bands of cellulose at around $3340 \mathrm{~cm}^{-1}$ (O-H stretching), $2900 \mathrm{~cm}^{-1}$ (C-H stretching), $1310 \mathrm{~cm}^{-1}$ $\left(\mathrm{O}-\mathrm{H}\right.$ bending) and $1030 \mathrm{~cm}^{-1}$ (C-O stretching) (Pecoraro et al., 2008). The presence in the spectra of PGMA/BC and PGMA-MBA/BC of the absorption bands at $1724 \mathrm{~cm}^{-1}$ assigned to the $\mathrm{C}=\mathrm{O}$ stretching vibration, and 1252, 906 and $844 \mathrm{~cm}^{-1}$ attributable to the $\mathrm{C}-\mathrm{O}-\mathrm{C}$ epoxide ring stretching (Tapeinos et al., 2013; Yang, Xu, Pispas, \& Zhang, 2013; Yuan et al., 2017), supports the inclusion of PGMA inside the $\mathrm{BC}$ network. The existence of the absorption bands at $1720 \mathrm{~cm}^{-1}$ $(\mathrm{C}=\mathrm{O}$ stretching vibration of the ester moiety) (Guzmán et al., 2017) in the spectrum of PPEGMA/BC nanocomposite, corroborates the incorporation of PPEGMA into the $\mathrm{BC}$ three-dimensional structure.

\subsection{Morphology and topography of the BC-based nanocomposites}

The BC-based nanocomposites were characterized by SEM and AFM to acquire information about their morphology and topography, which is also important for the evaluation of their potentialities for specific applications. Fig. 3 shows the SEM micrographs of the surface of pure BC and PGMA/BC, PGMA-MBA/BC and PPEGMA/BC nanocomposites. The three-dimensional nanofibrillar network characteristic of the $\mathrm{BC}$ surface morphology is not clearly visible on the surface of the three nanocomposites because the nanofibrils are imbedded in the respective polymer matrix (i.e. PGMA, cross-linked PGMA and PPEGMA). This is further validated by the AFM 2D topography images displayed in Fig. 4, which show the defined fibril network of $\mathrm{BC}$ and the change in surface texture with the incorporation of PGMA, cross-linked PGMA and PPEGMA polymers. Furthermore, the nanocomposites exhibit different surface roughness ( $R_{\mathrm{a}}$, arithmetic average roughness) depending on the polymer matrix, as depicted in Table 2 . The pure BC presents a surface roughness of $37.7 \pm 1.3 \mathrm{~nm}$, which is higher than the value $\left(R_{\mathrm{q}}=25.2 \pm 3.6 \mathrm{~nm}\right.$, root mean-square roughness) recently reported for an oven-dried BC sample (Alonso, Faria, Mohammadkazemi, et al., 2018), but much lower than the value $(321 \mathrm{~nm})$ obtained by for a freeze-dried BC sample (Jia et al., 2017). The incorporation of $61 \mathrm{wt} . \%$ of PGMA and $87 \mathrm{wt} . \%$ of PPEGMA inside the BC porous structure promoted a decrease of about 8.5 and $29 \%$ of the surface roughness to $34.5 \pm 16.6 \mathrm{~nm}$ and $26.8 \pm 0.1 \mathrm{~nm}$, respectively, when compared to pure BC. In contrast, the nanocomposite composed of cross-linked PGMA (67 wt.\%) presents a higher a $R_{\mathrm{a}}$ value $(51.4 \pm 2.1 \mathrm{~nm})$ than $\mathrm{BC}$ and PGMA/BC nanocomposite This last result demonstrates that use of a non-cross-linked or cross-linked polymer clearly influences the properties of the ensuing nanocomposite because of the level of chain entanglement. These differences in surface roughness suggest that the surface properties of the nanocomposites will be different, as discussed in the paragraphs below.

\subsection{Surface properties of the BC-based nanocomposites by IGC}

The surface properties of the three BC-based nanocomposites were evaluated using IGC. Several physicochemical properties, namely surface area $\left(S_{B E T}\right)$, monolayer capacity $\left(n_{m}\right)$, dispersive component of surface energy $\left(\gamma_{s}^{d}\right)$, Lewis acidic $\left(K_{a}\right)$ and basic $\left(K_{b}\right)$ constants, were determined to understand the energetic interactions at the surface of native $\mathrm{BC}$ and $\mathrm{BC}$-based nanocomposites (Table 3 ). The heterogeneity profile (Fig. 5) and the specific free energy of adsorption $\left(\Delta G_{s}^{s p}\right)$ (Fig. 6) were also investigated.

According to Table 3, pure BC shows a BET specific surface area of $3.94 \mathrm{~m}^{2} \mathrm{~g}^{-1}$ and a monolayer capacity of $10.38 \mu \mathrm{mol} \mathrm{g}^{-1}$, which are

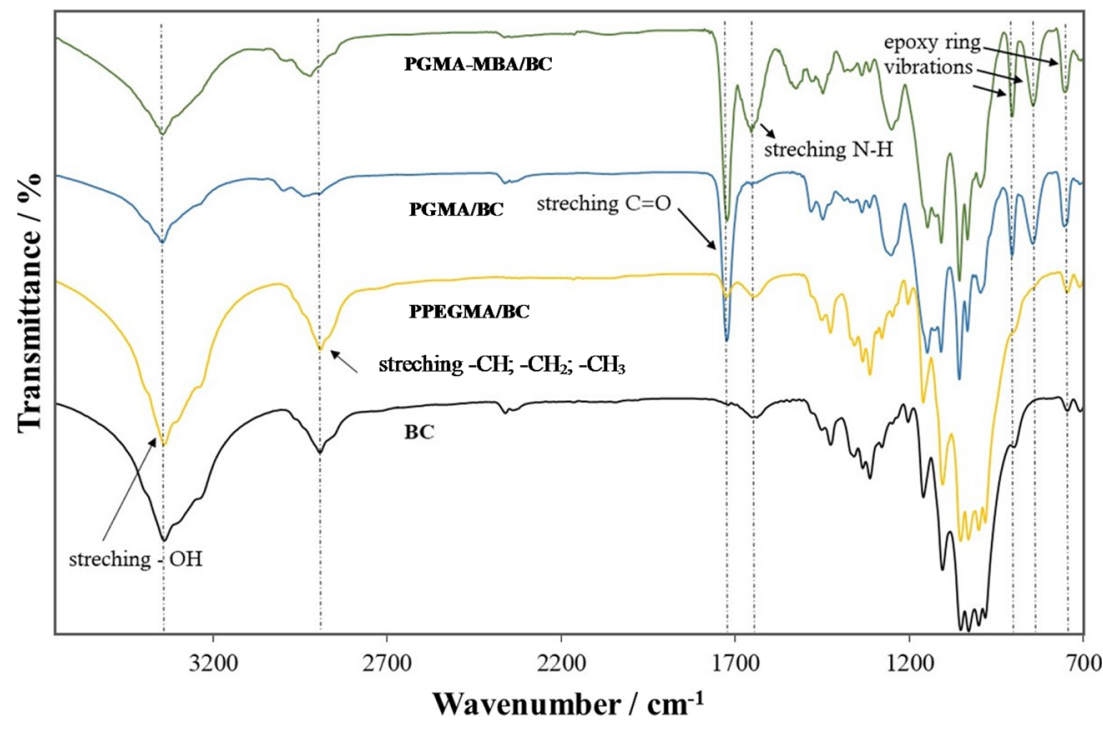

Fig. 2. ATR-FTIR spectra of BC, PGMA/BC, PGMA-MBA/BC and PPEGMA/BC nanocomposites. 

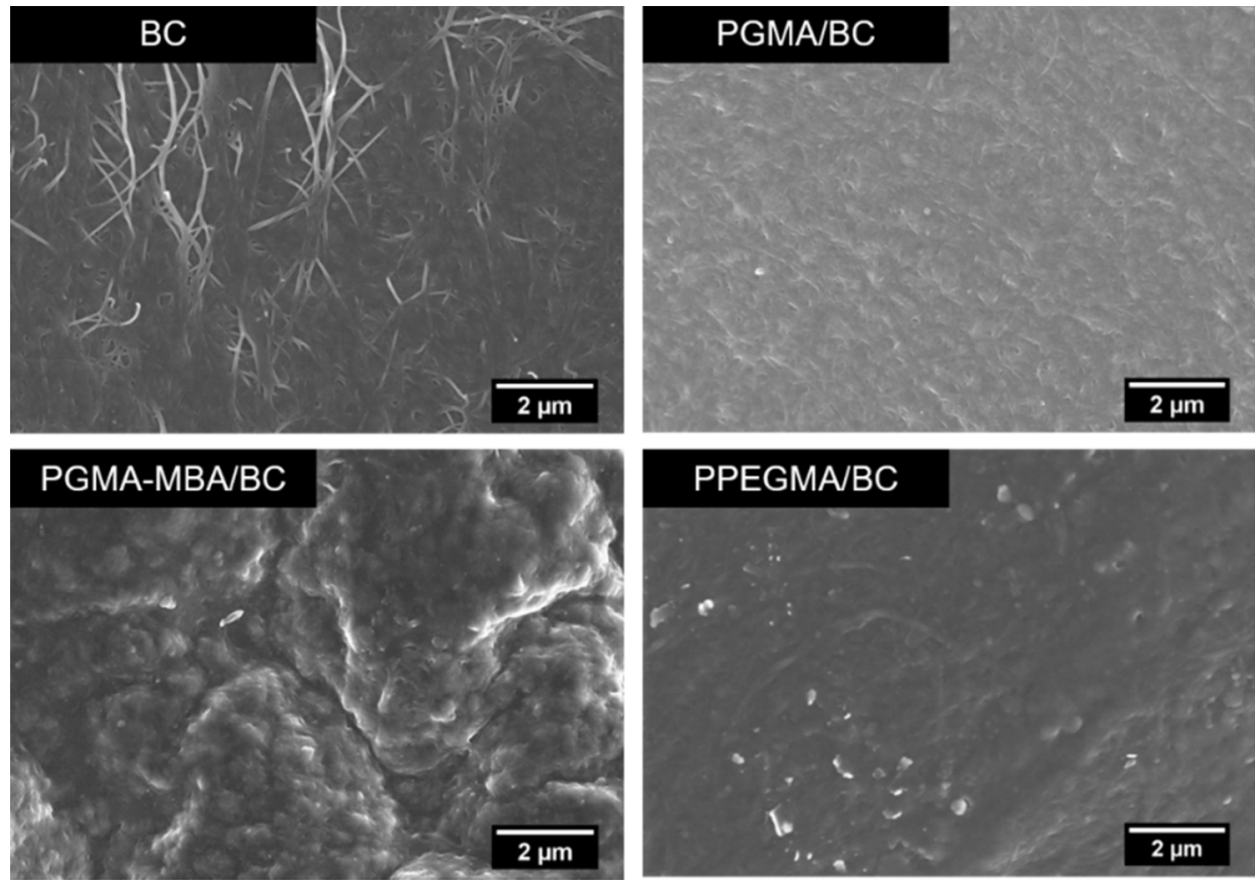

Fig. 3. SEM micrographs of the surface of pure BC, and PGMA/BC, PGMA-MBA/BC and PPEGMA/BC nanocomposites.
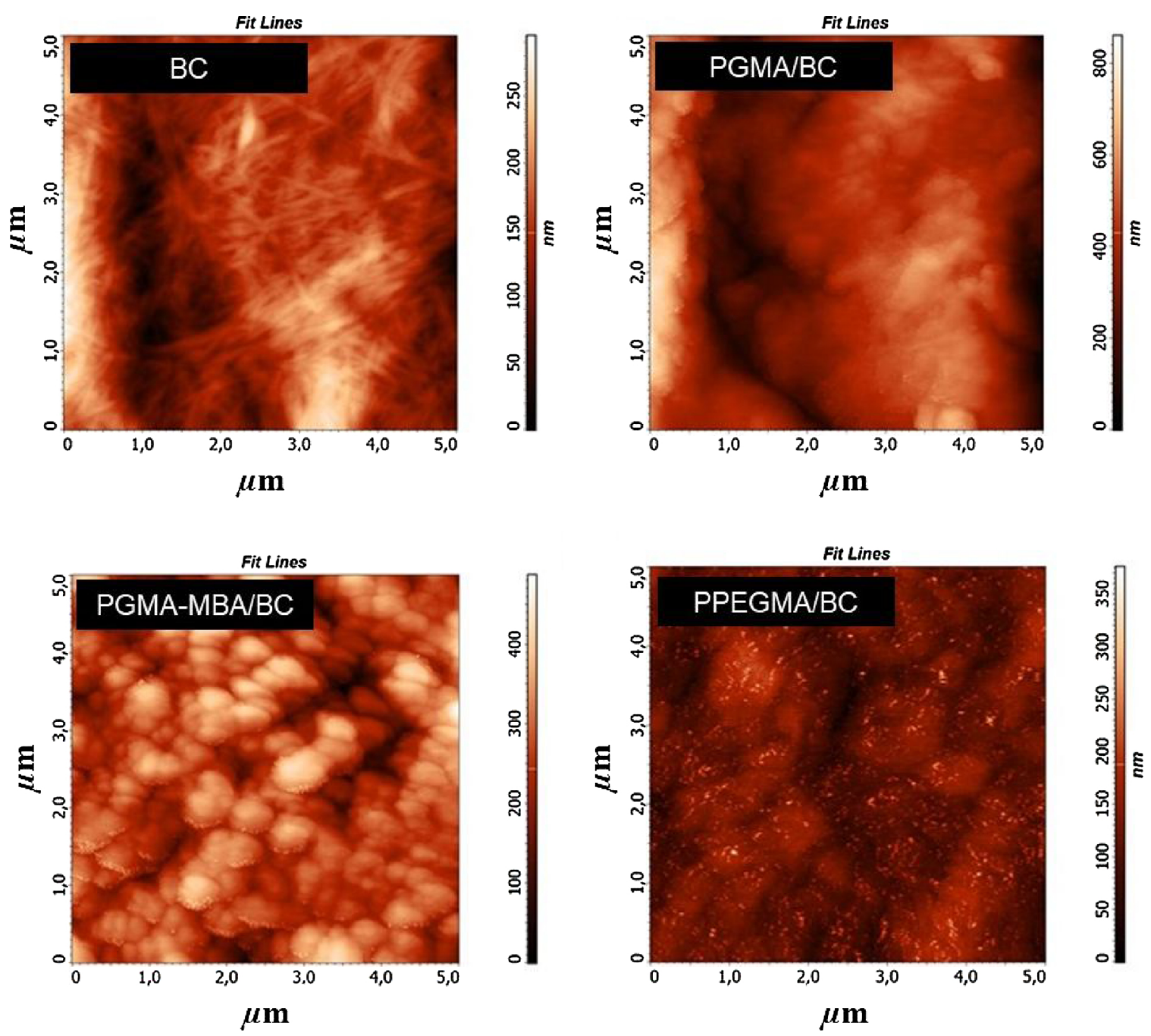

Fig. 4. AFM $2 D$ images $\left(5 \times 5 \mu \mathrm{m}^{2}\right)$ of pure BC, and PGMA/BC, PGMA-MBA/BC and PPEGMA/BC nanocomposites. 
Table 3

IGC surface physicochemical properties of BC, and PGMA/BC, PGMA-MBA/BC and PPEGMA/BC nanocomposites.

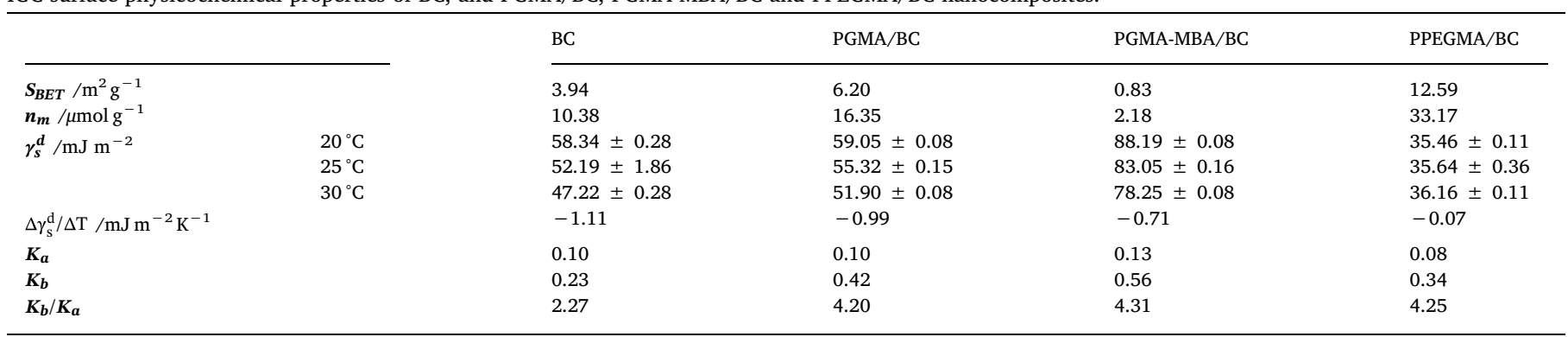

$S_{B E T}:$ surface area; $n_{m}$ : monolayer capacity; $\gamma_{s}^{d}$ : dispersive surface energy; $K_{a}$ : acidic constant; $K_{b}$ : basic constant.
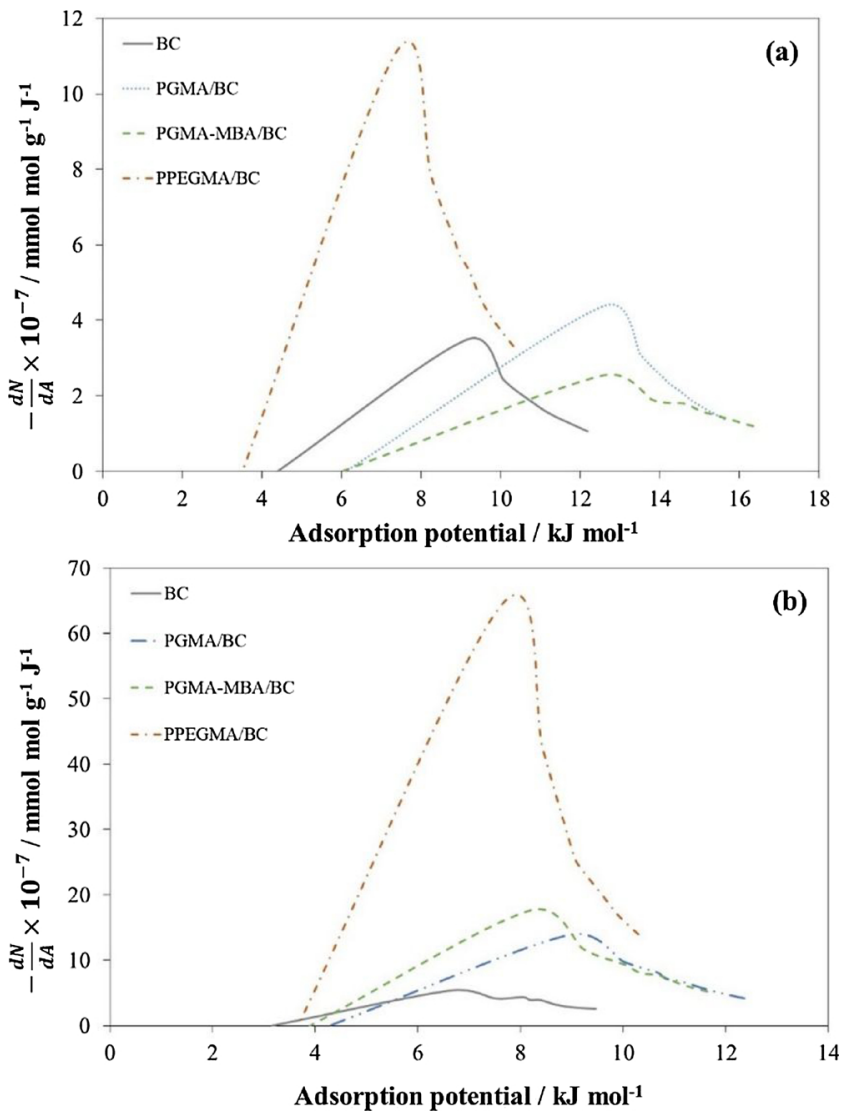

Fig. 5. Heterogeneity profile with (a) n-octane and (b) dichloromethane from BC, PGMA/BC, PGMA-MBA/BC and PPEGMA/BC nanocomposites at $25^{\circ} \mathrm{C}$.

higher than the values obtained for BC films at $20^{\circ} \mathrm{C}, S_{B E T}=1.94$ $\mathrm{m}^{2} \mathrm{~g}^{-1}$ and $n_{m}=0.005 \mathrm{mmol} \mathrm{g}^{-1}$ (Castro et al., 2015), but lower than the $S_{B E T}$ value $\left(4.59 \mathrm{~m}^{2} \mathrm{~g}^{-1}\right.$ at $\left.25^{\circ} \mathrm{C}\right)$ recently reported for an ovendried BC (Alonso, Faria, Ferreira, et al., 2018). Furthermore, the nanocomposite containing the cross-linked version of PGMA polymer (i.e. PGMA-MBA/BC) presents values of $S_{B E T}$ and $n_{m}$ lower than those of BC, whereas the inclusion of a polymer bearing hydroxyl pendent groups inside the $\mathrm{BC}$ network originated a nanocomposite (i.e. PPEGMA/BC) with $S_{B E T}$ and $n_{m}$ values that are three times higher than the ones obtained for pure BC.

The $S_{B E T}$ increase can be due to the particle size decrease or rugosities increase in the material surface. As the obtained $R_{\mathrm{q}}$ values were not correlated with $S_{B E T}$, the molecular changes, above referred, were not detected by AFM analysis. As IGC uses small molecules ( $n$-octane) as probes, which can be inserted in the structural heterogeneities (nanorugosities) at the material, it's possible to detect changes at a molecular level. Thus, the $S_{B E T}$ increase was correlated to the pendent

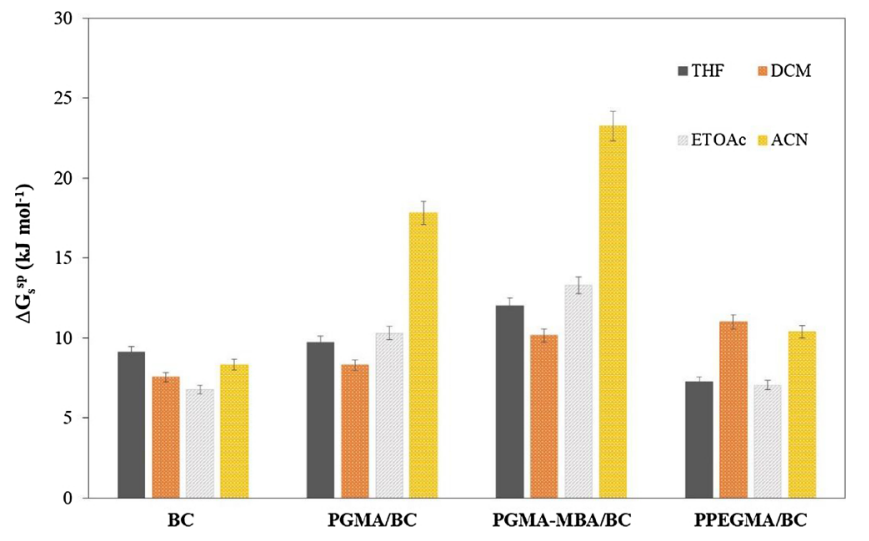

Fig. 6. Specific free energy of adsorption $\left(\Delta G_{s}^{s p}\right)$ of BC, PGMA/BC, PGMA-MBA/ $\mathrm{BC}$ and PPEGMA/BC nanocomposites, with polar probes: THF - tetrahydrofuran, DCM - dichloromethane, EtOAc - ethyl acetate and ACN - acetonitrile, at $25^{\circ} \mathrm{C}$.

chain/groups inside the $\mathrm{BC}$ network (nanorugosities increase), and the $S_{B E T}$ decrease was correlated to the cross-linked polymer which decrease the pendent chain/groups (nanorugosities decrease).

These BET isotherm measurements can be correlated with the heterogeneity of the surface; thus, Fig. 5 shows the heterogeneity profiles of $\mathrm{BC}$ and the three nanocomposites at $25^{\circ} \mathrm{C}$ using $n$-octane and dichloromethane as non-polar and polar probes, respectively. For the $n$ octane probe (Fig. 5a), PPEGMA/BC presents the lowest adsorption potential $\left(A_{\max }=7.38 \mathrm{~kJ} \mathrm{~mol}^{-1}\right), \quad$ followed by $\mathrm{BC}$ $\left(A_{\max }=9.15 \mathrm{~kJ} \mathrm{~mol}^{-1}\right)$, PGMA/BC $\left(A_{\max }=12.6 \mathrm{~kJ} \mathrm{~mol}^{-1}\right)$ and PGMAMBA/BC $\left(A_{\max }=12.6\right.$ and $\left.14.8 \mathrm{~kJ} \mathrm{~mol}^{-1}\right)$. While PPEGMA/BC nanocomposite exhibits a surface with high number of active sites but less energetic, PGMA-MBA/BC has a surface with more energetic dispersive active sites. The less pronounced energetic heterogeneity of PPEGMA/ $\mathrm{BC}$ can explain the higher $S_{B E T}$ value of this nanocomposite (12.59 $\mathrm{m}^{2} \mathrm{~g}^{-1}$, Table 3).

In the case of the dichloromethane (acid) probe (Fig. 5b), there is a different tendency with $\mathrm{BC}$ exhibiting the lowest adsorption potential, followed by PPEGMA/BC, PGMA-MBA/BC and PGMA/BC. The differences in the energetic profiles is a clear indication of the variances in polarity among nanocomposites.

The dispersive component of surface energy $\left(\gamma_{s}^{d}\right)$, which is caused by non-polar long-range interactions (London forces), decreased with temperature rise from 20 to $30^{\circ} \mathrm{C}$ for both pure $\mathrm{BC}$ and the three nanocomposites. These negative values of the temperature dependence of the surface energy (Table 3) are associated with the exothermic nature of the adsorption process and to the chain freedom. Thus, the lowest of $\Delta \gamma_{\mathrm{s}}^{\mathrm{d}} / \Delta \mathrm{T}$ obtained to the nanocomposites indicate the polymethacrylate incorporation into the BC.

The $\gamma_{s}^{d}$ values obtained for BC ranged from $47.22 \pm 0.28 \mathrm{~mJ} \mathrm{~m}^{-2}$ at $30{ }^{\circ} \mathrm{C}$ to $58.34 \pm 0.28 \mathrm{~mJ} \mathrm{~m}^{-2}$ at $20^{\circ} \mathrm{C}$. Although these values are 
higher than those obtained in previous studies for oven-dried BC, namely $39.64 \mathrm{~mJ} \mathrm{~m}^{-2}$ at $20^{\circ} \mathrm{C}$ (Castro et al., 2015), $39.21 \mathrm{~mJ} \mathrm{~m}^{-2}$ at $25^{\circ} \mathrm{C}$ (Mohammadkazemi et al., 2017) and $37.7 \pm 0.9 \mathrm{~mJ} \mathrm{~m}^{-2}$ at $25^{\circ} \mathrm{C}$ (Alonso, Faria, Mohammadkazemi, et al., 2018), Pommet et al. reported a $\gamma_{s}^{d}$ value of $61 \mathrm{~mJ} \mathrm{~m}^{-2}$ (Pommet et al., 2008). These values may be due to the: (i) BC extrusion differ between strains of cellulose producing bacteria; and/or (ii) the different synthesis conditions influence the cellulose chains arrangement and, consequently, the cellulose type produced, which influence the interaction between the $\mathrm{BC}$ surfaces and the probes. Nevertheless, nanofibrillated cellulose (NFC), which is another nanoscale form of cellulose, possesses comparable values of $\gamma_{s}^{d}=32.4-49.5 \mathrm{~mJ} \mathrm{~m}^{-2}$ at $25^{\circ} \mathrm{C}$ (Deepa et al., 2015) and $\gamma_{s}^{d}=41.7-$ $51.5 \mathrm{~mJ} \mathrm{~m}^{-2}$ at $40^{\circ} \mathrm{C}$ (Gamelas, Pedrosa, Lourenço, \& Ferreira, 2015).

Despite the slight increase of the dispersive component of surface energy of PGMA/BC nanocomposite $\left(55.32 \pm 0.15 \mathrm{~mJ} \mathrm{~m}^{-2}\right.$ at $\left.25^{\circ} \mathrm{C}\right)$ when compared to $\mathrm{BC}$, the nanocomposite containing the cross-linked version of PGMA polymer promoted an increase of about $59 \%$ at $25{ }^{\circ} \mathrm{C}$ $\left(83.05 \pm 0.16 \mathrm{~mJ} \mathrm{~m}^{-2}\right.$, Table 3$)$. This augment indicates that the incorporation of a polymer bearing epoxide pendent groups inside the $\mathrm{BC}$ network originated nanocomposites with hydrophobic surfaces, which is in line with a small water uptake capacity (Table 2). Furthermore, the $A_{\text {max }}$ peak shift towards higher energies in the heterogeneity profile (Fig. 5a) also points to a higher hydrophobicity due to the energy increase of the non-polar active sites. On the contrary, the nanocomposite containing the polymer bearing hydroxyl pendent groups (i.e. PPEGMA/BC) presents the lowest $\gamma_{s}^{d}$ values $\left(35.64 \pm 0.36 \mathrm{~mJ} \mathrm{~m}^{-2}\right.$ at $25{ }^{\circ} \mathrm{C}$ ), which is indicative of a more hydrophilic surface than $\mathrm{BC}$, as in fact demonstrated by its very high water uptake capacity (ca. $430 \%$, Table 2) and less energetic non-polar active sites (Fig. 5a).

The acid-base nature of the surface of the three BC-based nanocomposites was evaluated based on their interactions with different polar probes, namely tetrahydrofuran, dichloromethane, ethyl acetate and acetonitrile. It is important to bear in mind that (i) the polarity of the selected probes increases in the following order: dichloromethane $<$ tetrahydrofuran $<$ ethyl acetate $<$ acetonitrile, and (ii) dichloromethane is an acid probe, tetrahydrofuran is a base probe, ethyl acetate is an amphoteric probe predominantly basic, and acetonitrile is an amphoteric probe (Gamelas, 2013). The specific free energy of adsorption and the Lewis acid-base constants were determined, and the corresponding data is presented in Fig. 6 and Table 3.

The $\Delta G_{s}^{s p}$ values of BC slightly increased in order of ethyl acetate $\left(6.76 \mathrm{~kJ} \mathrm{~mol}^{-1}\right)<$ dichloromethane $\quad\left(7.54 \mathrm{~kJ} \mathrm{~mol}^{-1}\right)<$ acetonitrile $\left(8.32 \mathrm{~kJ} \mathrm{~mol}^{-1}\right)<$ tetrahydrofuran $\left(9.08 \mathrm{~kJ} \mathrm{~mol}^{-1}\right)$, indicating a surface amphoteric behaviour but with a predominantly acidic character (Fig. 6) as discussed in literature (Alonso, Faria, Ferreira, et al., 2018). A general increase in $\Delta G_{s}^{s p}$ is immediately visible in Fig. 6 for all the probes after the inclusion of polymers bearing epoxide pendent groups inside the $\mathrm{BC}$ porous network, i.e. PGMA/BC and PGMA-MBA/BC nanocomposites, which confirms the increase of polar groups on the surface of these nanocomposites. Moreover, the amphoteric acetonitrile probe displays a stronger interaction with the PGMA/BC and PGMA$\mathrm{MBA} / \mathrm{BC}$ nanocomposites reaching the maximum $\Delta G_{s}^{s p}$ values of 17.80 and $23.23 \mathrm{~kJ} \mathrm{~mol}^{-1}$, respectively, that is indicative of acidic (electron acceptor) and basic (electron donor) character on their surfaces.

PPEGMA/BC on the other hand is the nanocomposite displaying the lowest interaction with the polar probes, except for the dichloromethane probe where it reaches a maximum $\Delta G_{s}^{s p}$ value of $11.01 \mathrm{~kJ} \mathrm{~mol}^{-1}$. This observation is supported by the energetic profile obtained from the acid probe (dichloromethane) depicted in Fig. 5b and can be ascribed to a lower concentration of polar surface groups. Furthermore, the higher $\Delta G_{s}^{s p}$ value of PPEGMA/BC with the acid probe points to a surface with a more basic than acidic character.

Regarding the Lewis acid-base constants, the $K_{\mathrm{a}}$ and $K_{\mathrm{b}}$ values of pure $B C$ were 0.10 and 0.23 , respectively, confirming that the surface of $\mathrm{BC}$ is predominantly basic $\left(K_{\mathrm{b}} / K_{\mathrm{a}}=2.27\right.$, Table 3$)$. The surface basicity exhibited by $\mathrm{BC}$ is higher than the values found in previous studies which reported $K_{\mathrm{b}} / K_{\mathrm{a}}$ ratios of 0.55 (Castro et al., 2015), 0.75 (Alonso, Faria, Ferreira, et al., 2018) and 1.83 (Mohammadkazemi et al., 2017), but lower than the results reported by Pommet et al., with a $K_{\mathrm{a}}$ of 0.11 , $K_{\mathrm{b}}$ of 0.41 and $K_{\mathrm{b}} / K_{\mathrm{a}}$ of 3.73 (Pommet et al., 2008). This is probably also a result of small differences in surface morphology and cellulose structural groups orientation, that affect the interaction between the BC surfaces and the probes. Although the $K_{\mathrm{a}}$ constant of the three nanocomposites did not suffer a substantial change when compared with BC, the basic character is quite different among the materials. In fact, the ratio between the basic and acidic surface constants increased from 2.27 for BC to 4.20 for PGMA/BC, 4.25 for PPEGMA/BC and 4.31 for PGMA-MBA/BC (Table 3). The augment of the basicity ratio of about 85 - $90 \%$ validates the enhancement of the Lewis basic character of the nanocomposites surface when compared to $\mathrm{BC}$, which is a direct result of the inclusion of basic groups. Therefore, PGMA-MBA/BC is the nanocomposite possessing the higher concentrations of electron-donating surface functional groups. These results correlate well with the specific free energy of adsorption data discussed above (Fig. 6).

\subsection{Cluster analysis}

Overall the three nanocomposite materials exhibit distinct structural, morphological and surface properties as discussed above. Nevertheless, and to confirm possible similarities among them, a hierarchically agglomerative clustering analysis was carried out by gradually merging single variables into extensive groups according to their features similarities. The dispersive component of surface free energy $\left(\gamma_{s}^{d}\right)$, adsorption potential $\left(A_{\max }\right)$ of $n$-octane, acid-base character $\left(K_{b} / K_{a}\right)$ ratio, specific component of surface free energy $\left(\Delta G_{s}^{s p}\right)$, surface area $\left(S_{B E T}\right)$, surface roughness $\left(R_{a}\right)$ and $C / O$ ratio were the selected variables for the agglomerative method. Fig. 7 depicts the dendrogram of the above-mentioned variables, where it is possible to observe three clusters. The first cluster presented a similarity of about $95 \%$ between both samples (BC and PGMA/BC), whereas the second cluster (PPEGMA/BC) showed a similarity of $c a$. $79 \%$ with respect to the first cluster. In turn, the third and last cluster (PGMA-MBA/BC) exhibited a low similarity (close to $17 \%$ ) with the remaining nanocomposites.

The hierarchical clustering suggests that the incorporation of $61 \mathrm{wt}$. $\%$ of a polymer bearing epoxide pendent groups (i.e. PGMA) inside the $\mathrm{BC}$ porous network originates a nanocomposite (PGMA/BC) with quite similar properties to $\mathrm{BC}$, whereas the inclusion of $87 \mathrm{wt} . \%$ of a polymer containing hydroxyl pendent groups (i.e. PPEGMA) yields a nanocomposite (PPEGMA/BC) with a lower level of similarity towards pure BC and PGMA/BC. Conversely, the nanocomposite composed of crosslinked PGMA and BC (i.e. PGMA-MBA/BC) exhibits significant dissimilarities with the other two nanocomposites as well as with pure BC. In fact, the incorporation of $67 \mathrm{wt} . \%$ of cross-linked PGMA into the BC

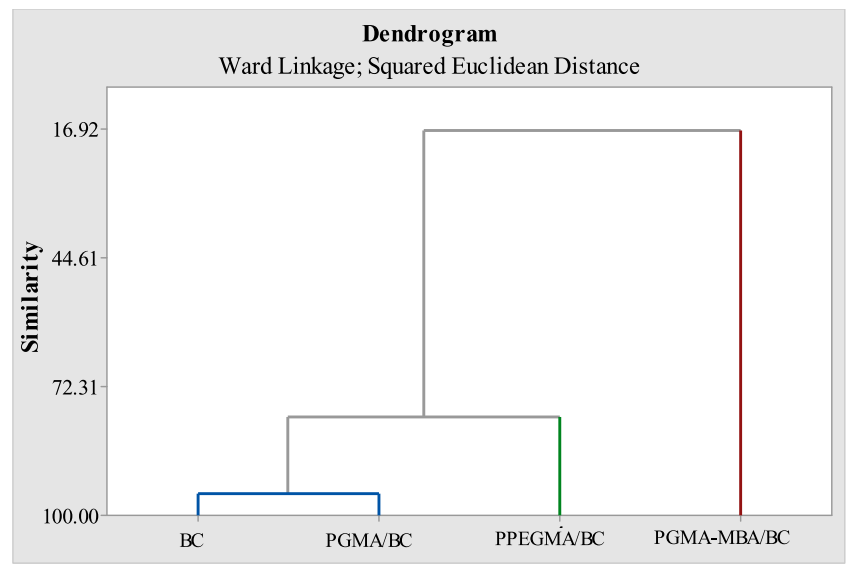

Fig. 7. Dendrogram of pure BC and PGMA/BC, PGMA-MBA/BC and PPEGMA/ BC nanocomposites using ICG parameters. 
three-dimensional network originated the most divergent results in terms of: $\gamma_{s}^{d}, A_{\max }, \Delta G_{s}^{s p}$ and $R_{a}$, as clearly discussed in the above paragraphs.

In this perspective, IGC proved once again to be an excellent tool for surface characterization of $\mathrm{BC}$ and its nanocomposites. The evaluation of the surface behaviour of the three nanocomposites in contact with polar and non-polar materials can contribute to foresee the potential applications of these materials. For example, while the PGMA-MBA/BC nanocomposite can be used as a functional hydrophobic material with an amphoteric (but predominantly basic) surface character for applications where the surface area is not a decisive factor, the PPEGMA/BC nanocomposite can be applied as a functional hydrophilic material for applications requiring high surface area and basic surface properties.

\section{Conclusions}

Nanocomposites consisting of either poly(glycidyl methacrylate), cross-linked poly(glycidyl methacrylate) or poly(poly(ethylene glycol) methacrylate) supported on the BC three-dimensional porous structure were successfully prepared and characterized regarding their physicochemical surface properties by IGC. The dispersive component of surface energy $\left(\gamma_{s}^{d}\right)$ varied between $35.64-83.05 \mathrm{~mJ} \mathrm{~m}^{-2}$ at $25^{\circ} \mathrm{C}$. Overall, the surfaces of the nanocomposites were rendered with a predominant basic character $\left(K_{\mathrm{b}} / K_{\mathrm{a}}\right.$ of $\left.4.20-4.31\right)$. The nanocomposite composed of a cross-linked polymer bearing epoxide pendant groups exhibits the higher specific interactions with polar probes, and despite the reduced surface area $\left(S_{B E T}=0.83 \mathrm{~m}^{2} \mathrm{~g}^{-1}\right)$ and monolayer capacity $\left(n_{m}=2.18\right.$

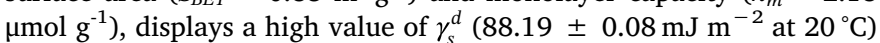
and an amphoteric (but predominantly basic) surface character. In view of these results, the potential of IGC to differentiate between the nanocomposite materials developed in the present study was confirmed, which enables the prediction of their interactions with other materials, and consequently assess their suitability for specific applications.

\section{Acknowledgments}

The authors acknowledge the National Program for Scientific Equipment Renewal, POCI 2010, for sponsoring the IGC work (FEDER and Foundation for the Science and Technology), and project CICECO Aveiro Institute of Materials, POCI-01-0145-FEDER-007679 (FCT Ref. UID/CTM/50011/ 2013), financed by national funds through the FCT/ MEC and when appropriate co-financed by FEDER under the PT2020 Partnership Agreement. The Portuguese Foundation for Science and Technology (FCT) is also acknowledged for the post-doctoral grant to C. Vilela (SFRH/BPD/84168/2012), and research contract under Investigador FCT to C.S.R. Freire (IF/01407/2012).

\section{References}

Alonso, E., Faria, M., Ferreira, A., \& Cordeiro, N. (2018). Influence of the matrix and polymerization methods on the synthesis of BC/PANi nanocomposites: An IGC study. Cellulose, 25(4), 2343-2354.

Alonso, E., Faria, M., Mohammadkazemi, F., Resnik, M., Ferreira, A., \& Cordeiro, N (2018). Conductive bacterial cellulose-polyaniline blends: Influence of the matrix and synthesis conditions. Carbohydrate Polymers, 183, 254-262.

Amin, M. C. I. M., Ahmad, N., Halib, N., \& Ahmad, I. (2012). Synthesis and characterization of thermo- and pH-responsive bacterial cellulose/acrylic acid hydrogels for drug delivery. Carbohydrate Polymers, 88(2), 465-473.

Beaumont, M., Kondor, A., Plappert, S., Mitterer, C., Opietnik, M., Potthast, A., et al. (2017). Surface properties and porosity of highly porous, nanostructured cellulose II particles. Cellulose, 24(1), 435-440.

Bozkurt, A., \& Karadedeli, B. (2007). Copolymers of 4(5)-vinylimidazole and ethyleneglycol methacrylate phosphate: Synthesis and proton conductivity properties. Reactive \& Functional Polymers, 67, 348-354.

Buyanov, A. L., Gofman, I. V., Revel'skaya, L. G., Khripunov, A. K., \& Tkachenko, A. A. (2010). Anisotropic swelling and mechanical behavior of composite bacterial cellulose-poly(acrylamide or acrylamide-sodium acrylate) hydrogels. Journal of the Mechanical Behavior of Biomedical Materials, 3(1), 102-111.

Castro, C., Cordeiro, N., Faria, M., Zuluaga, R., Putaux, J. L., Filpponen, I., et al. (2015). In-situ glyoxalization during biosynthesis of bacterial cellulose. Carbohydrate Polymers, 126, 32-39.
Cordeiro, N., Gouveia, C., Moraes, A. G. O., \& Amico, S. C. (2011). Natural fibers characterization by inverse gas chromatography. Carbohydrate Polymers, 84(1), 110-117.

Deepa, B., Abraham, E., Cordeiro, N., Mozetic, M., Mathew, A. P., Oksman, K., et al. (2015). Utilization of various lignocellulosic biomass for the production of nanocellulose: a comparative study. Cellulose, 22(2), 1075-1090.

Figueiredo, A. G. P. R., Figueiredo, A. R. P., Alonso-Varona, A., Fernandes, S. C. M., Palomares, T., Rubio-Azpeitia, E., et al. (2013). Biocompatible bacterial cellulosepoly(2-hydroxyethyl methacrylate) nanocomposite films. BioMed Research International, 698141, 1-14.

Figueiredo, A. R. P., Figueiredo, A. G. P. R., Silva, N. H. C. S., Barros-Timmons, A., Almeida, A., Silvestre, A. J. D., et al. (2015). Antimicrobial bacterial cellulose nanocomposites prepared by in situ polymerization of 2-aminoethyl methacrylate. Carbohydrate Polymers, 123, 443-453.

Gadim, T. D. O., Figueiredo, A. G. P. R., Rosero-Navarro, N. C., Vilela, C., Gamelas, J. A. F., Barros-Timmons, A., et al. (2014). Nanostructured bacterial cellulose-poly(4styrene sulfonic acid) composite membranes with high storage modulus and protonic conductivity. ACS Applied Materials \& Interfaces, 6(10), 7864-7875.

Gamelas, J. A. F. (2013). The surface properties of cellulose and lignocellulosic materials assessed by inverse gas chromatography: a review. Cellulose, 20(6), 2675-2693.

Gamelas, J. A. F., Pedrosa, J., Lourenço, A. F., \& Ferreira, P. J. (2015). Surface properties of distinct nanofibrillated celluloses assessed by inverse gas chromatography. Colloids and Surfaces A, Physicochemical and Engineering Aspects, 469, 36-41.

Guzmán, G., Nava, D. P., Vazquez-Arenas, J., \& Cardoso, J. (2017). Design of a zwitterion polymer electrolyte based on poly[poly (ethylene glycol) methacrylate]: The effect of sulfobetaine group on thermal properties and ionic conduction. Macromolecular Symposia, 374, 1600136.

Hobzova, R., Duskova-Smrckova, M., Michalek, J., Karpushkin, E., \& Gatenholm, P. (2012). Methacrylate hydrogels reinforced with bacterial cellulose. Polymer International, 61(7), 1193-1201.

Jia, Y., Wang, X., Huo, M., Zhai, X., Li, F., \& Zhong, C. (2017). Preparation and characterization of a novel bacterial cellulose/chitosan bio-hydrogel. Nanomaterials and Nanotechnology, 7, 1-8.

Jiang, F., \& Hsieh, Y.-L. (2014). Super water absorbing and shape memory nanocellulose aerogels from TEMPO-oxidized cellulose nanofibrils via cyclic freezing-thawing. Journal of Materials Chemistry A, 2(2), 350-359.

Lapčík, L., Otyepka, M., Otyepková, E., Lapčíková, B., Gabriel, R., Gavenda, A., et al. (2016). Surface heterogeneity: Information from inverse gas chromatography and application to model pharmaceutical substances. Current Opinion in Colloid \& Interface Science, 24, 64-71.

Mashkour, M., Rahimnejad, M., \& Mashkour, M. (2016). Bacterial cellulose-polyaniline nano-biocomposite: A porous media hydrogel bioanode enhancing the performance of microbial fuel cell. Journal of Power Sources, 325, 322-328.

Mohammadi-Jam, S., \& Waters, K. E. (2014). Inverse gas chromatography applications: A review. Advances in Colloid and Interface Science, 212, 21-44.

Mohammadkazemi, F., Aguiar, R., \& Cordeiro, N. (2017). Improvement of bagasse fiber-cement composites by addition of bacterial nanocellulose: an inverse gas chromatography study. Cellulose, 24(4), 1803-1814.

Muzammil, E. M., Khan, A., \& Stuparu, M. C. (2017). Post-polymerization modification reactions of poly(glycidyl methacrylate)s. RSC Advances, 7(88), 55874-55884.

Pecoraro, E., Manzani, D., Messaddeq, Y., \& Ribeiro, S. J. L. (2008). Bacterial cellulose from Glucanacetobacter xylinus: Preparation, properties and applications. In M. N. Belgacem, \& A. Gandini (Eds.). Monomers, polymers and composites from renewable resources (pp. 369-383). Amsterdam: Elsevier.

Planinšek, O., \& Buckton, G. (2003). Inverse gas chromatography: Considerations about appropriate use for amorphous and crystalline powders. Journal of Pharmaceutical Sciences, 92(6), 1286-1294.

Pommet, M., Juntaro, J., Heng, J. Y. Y., Mantalaris, A., Lee, A. F., Wilson, K., et al. (2008) Surface modification of natural fibers using bacteria: depositing bacterial cellulose onto natural fibers to create hierarchical fiber reinforced nanocomposites. Biomacromolecules, 9(6), 1643-1651.

Saïdi, L., Vilela, C., Oliveira, H., Silvestre, A. J. D., \& Freire, C. S. R. (2017). Poly(Nmethacryloyl glycine)/nanocellulose composites as $\mathrm{pH}$-sensitive systems for controlled release of diclofenac. Carbohydrate Polymers, 169, 357-365.

Silvestre, A. J. D., Freire, C. S. R., \& Neto, C. P. (2014). Do bacterial cellulose membranes have potential in drug-delivery systems? Expert Opinion on Drug Delivery, 11(7), 1113-1124.

Tapeinos, C., Efthimiadou, E. K., Boukos, N., Charitidis, C. A., Koklioti, M., \& Kordas, G. (2013). Microspheres as therapeutic delivery agents: Synthesis and biological evaluation of pH responsiveness. Journal of Materials Chemistry B, 1(2), 194-203.

Trovatti, E., Serafim, L. S., Freire, C. S. R., Silvestre, A. J. D., \& Neto, C. P. (2011). Gluconacetobacter sacchari: An efficient bacterial cellulose cell-factory. Carbohydrate Polymers, 86(3), 1417-1420.

Ullah, H., Santos, H. A., \& Khan, T. (2016). Applications of bacterial cellulose in food cosmetics and drug delivery. Cellulose, 23(4), 2291-2314.

Ullah, H., Wahid, F., Santos, H. A., \& Khan, T. (2016). Advances in biomedical and pharmaceutical applications of functional bacterial cellulose-based nanocomposites. Carbohydrate Polymers, 150, 330-352.

Vilela, C., Gadim, T. D. O., Silvestre, A. J. D., Freire, C. S. R., \& Figueiredo, F. M. L. (2016). Nanocellulose/poly(methacryloyloxyethyl phosphate) composites as proton separator materials. Cellulose, 23(6), 3677-3689.

Vilela, C., Sousa, N., Pinto, R. J. B., Silvestre, A. J. D., Figueiredo, F. M. L., \& Freire, C. S. R. (2017). Exploiting poly(ionic liquids) and nanocellulose for the development of bio-based anion-exchange membranes. Biomass \& Bioenergy, 100, 116-125.

Yang, H., Xu, J., Pispas, S., \& Zhang, G. (2013). One-step synthesis of hyperbranched biodegradable polymer. RSC Advances, 3(19), 6853-6858.

Yuan, S., Zhang, J., Yang, Z., Tang, S., Liang, B., \& Pehkonen, S. O. (2017). Click functionalization of poly(glycidyl methacrylate) microspheres with triazole-4-carboxylic acid for the effective adsorption of $\mathrm{Pb}(\mathrm{II})$ ions. New Journal of Chemistry, 41(14), 6475-6488. 